\title{
"San Andrés jugaba a la taba, tanto perdía como ganaba". Estrategias sociales ante la suerte en Colmenar Viejo
}

En Colmenar Viejo (Madrid) y hasta los años setenta, jugaban los niños a la taba. Como en otras partes de Castilla' y casi de la misma manera que como Rodrigo Caro relata que se jugaba hace siglos ', el hueso de la rodilla del carnero servía para distribuir posiciones sociales: «rey», "verdugo», «carne» y «culo». Era un juego de todo tiempo. Se jugaba en la calle y sobre una superficie de tierra. De las dos caras más estrechas de la taba, la de «rey» correspondía a aquella cara que tiene un relieve, la de «verdugo» a la opuesta, la que no tiene relieve, la de «carne» a aquella de las dos caras anchas que es cóncava, y la de «culo» a la que es convexa. El «rey» ordenaba castigos, el «verdugo» ejecutaba las sanciones del «rey», el «culo» las recibía y el «carne» se libraba de ellas. Las sanciones consistían en un número variable - según la voluntad del «rey»- de golpes en el culo, que recibían el nombre de «tomates», o en la mano, llamados "cruzaos», dados con un «cinto». Las posiciones de «rey» y «verdugo» eran relativamente estables. Podían perderse y pasar a otros, pero también reforzarse y mantenerse durante tiempo, pues quien ya era "rey» o "verdugo», si al tirar le salía otra vez la cara correspondiente, alargaba el tiempo de mandato. Dada la particular morfología del hueso, la probabilidad de que se saque una de las dos caras anchas es mucho mayor que la de sacar una de las dos caras estrechas. Y aun entre éstas y debido a la carencia de relieve y a las ondulaciones de la cara que debe servir de asiento, la probabilidad de sacar «rey» es ligeramente menor que la de sacar «verdugo». La distribución de las posiciones sociales y su jerarquía se basa pues en la desigual probabilidad de que salga cada cara. Se ocupa una posición más alta cuanto menor es la probabilidad de que salga la cara que la otorga. El azar aunque variable siempre es selectivo.

1 Véase especialmente, J. Herrero: Juegos populares de Avila (Ávila: Diario de Ávila, 1986); I. SANZ: Juegos populares de Castilla y León (Valladolid: Castilla Ediciones, 1983). Sin embargo, en un registro actual de Andalucía, con parecida distribución de posiciones sociales se juega con papeletas, no con la taba. Ver A. GARcía Benitez, El folclore infantil andaluz (Sevilla: Editoriales Andaluzas Reunidas, 1988).

2 R. CARo, Días geniales o lúdricos, edición a cargo de J. P. Etienvre (Madrid: Espasa-Calpe, 1978), I, pp. 173 y ss. 

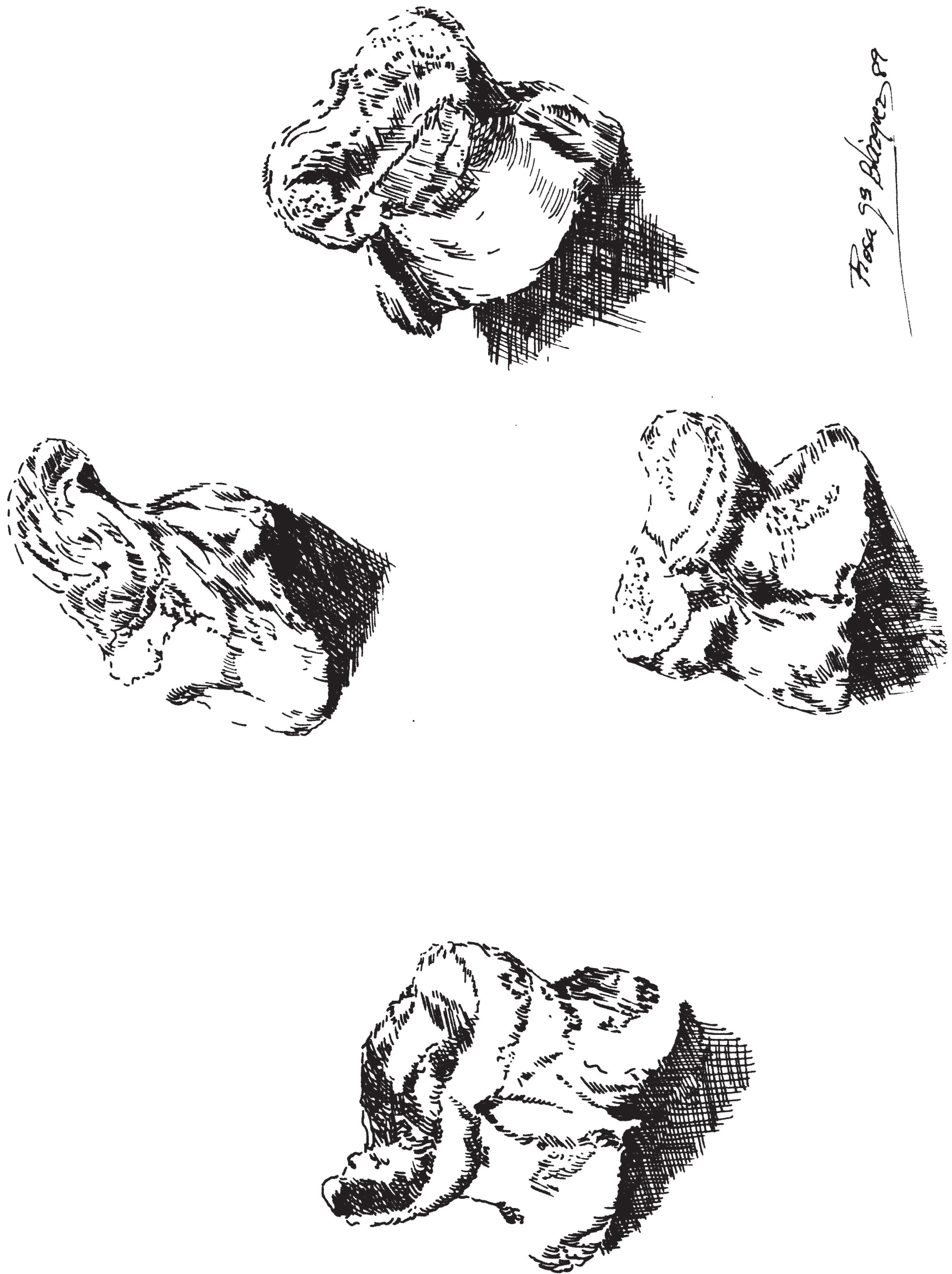

Flc. 1 
Los golpes eran reales. La arbitrariedad del «rey» era constantemente puesta a prueba. El «verdugo» cumplía con eficacia su cometido, si no, su puesto podía ser revocado. Quienes sacaban «culo» aguantaban y sufrían. $\mathrm{Y}$ quienes sacaban «carne» respiraban aliviados. Los niños «jugaban» con cosas serias. El juego se mueve generalmente entre las viejas categorías de las «bromas» y las «veras». Un eje que va de la broma a lo serio y por el que el desplazamiento se produce casi sin sentir. En este juego los golpes podían ser más fuertes de lo que se era capaz de aguantar y podían terminar en una verdadera pelea. Pero además este juego toma como suerte las posiciones sociales y las esquematiza en acciones graves, serias, que en los niños, sin embargo, se consideran simplemente un «juego».

Pero la taba también sirve para distribuir dinero. Actualmente, dos veces al año, los días de San Andrés (30 de noviembre) y de Santa Lucía (13 de diciembre), en Colmenar, los hombres juegan a la taba. Se juegan dinero. El juego consiste en tirar una sola taba sobre una mesa cubierta por un paño. Si sale «carne» se gana, si sale «culo» se pierde (ver fig. 1). Pero «carne» y «culo» designan las caras que en la modalidad de juego practicado por los niños eran «rey» y «verdugo». Como juego de adultos es un juego en serio. Las apuestas se hacen en dinero contante y se pagan inmediatamente. Quien tira la taba propone la cuantía de la apuesta y entrega el dinero a un crupier. La apuesta es cubierta por un número variable de personas - generalmente más de 6 y menos de 15 - que ponen dinero sobre la mesa y que el crupier se encarga de «casar» con lo que ha puesto quien tira la taba. Juega, por tanto, uno contra todos. Si gana se lleva todo él. Si pierde, el dinero se reparte entre los que han cubierto la apuesta. Si gana, puede seguir jugando y proponer otra apuesta de cuantía mayor que la anterior, que a su vez debe ser cubierta entre cuantos lo deseen. Sólo puede seguir jugando si sigue ganando. Si pierde, su puesto pasa a ser ocupado por otro tirador.

Las diferencias entre una y otra modalidad del juego de la taba son notorias. En una el código del juego toma como relevantes las cuatro caras, en la otra sólo dos. Precisamente las que tienen menos probabilidad de salir. Las dos caras restantes no tienen significación. La taba es un instrumento que genera un lenguaje susceptible de ser codificado de modo diverso ${ }^{3}$. En la primera modalidad cada jugada es efectiva, pues obligadamente ha da salir

\footnotetext{
3 A modo de ejemplo: R. CARo reseña las cuatro posiciones como «rey», «alguacil», "zapata» y «horca»; el Diccionario de Autoridades en la voz «taba»: «taba», "chuque», "carne», «culo»; el Diccionario Espasa: «carne», «culo», «tripa», «hoyo»; en prov. de Burgos (I. SANZ, op. cit.): «carne», «culo», «filis», "pencas»; en prov. de Ávila (J. HERrero, op. cit.): «rey», «verdugo», "panza», «ojete». No todas ellas son posiciones sociales, pero sí son posiciones distintas según la modalidad de juego: dar golpes, coger las tabas sin dejárselas caer, etc.
} 
alguna cara y así se refuerza una posición o se modifica. En la segunda, sólo determinadas jugadas modifican las situaciones. Si sale alguna de las caras anchas - lo que es más probable - no ocurre nada y hay que seguir tirando hasta que salga «carne» o «culo». La carencia de significación de algunas jugadas no resta interés al juego, al contrario, provoca suspense, incrementa la emoción.

En la primera modalidad se juegan posiciones sociales. En la segunda, dinero. El juego trata las posiciones sociales como si fueran múltiples y graduadas - además de ser susceptibles de ser ocupadas por cualquier persona con independencia de lo que pudieran haber sido anteriormente-. Pero trata el dinero como si fuera una cualidad, no una cantidad, que se conserva e incrementa o se pierde. $\mathrm{Ha}$ de ser el jugador el que dosifique la cuantía de la apuesta, aunque en teoría el juego le permitiría - si encontrara gente que le cubriera la apuesta- apostar todo lo que tiene en una sola jugada.

Pero además, los niños juegan con lo que realmente no tienen: posiciones sociales (o al menos con muchas de las posiciones sociales que realmente no tienen). Los hombres juegan con lo que tienen, se juegan lo que tienen. Esto es lo que muestra la diferencia que va de jugar en broma a jugar en serio. La seriedad es una categoría que aparece en aquellos juegos que someten al azar lo que los hombres han obtenido como y por necesidad.

\section{TIEMPOS Y ESPACIOS DE JUEGO}

Hasta 1841, según consta en el Archivo Parroquial, hubo una ermita dedicada a San Andrés y Santa Lucía en el lugar donde luego se construyó el depósito de agua. No hay constancia de qué celebraciones se hacían en ella. A primeros de este siglo se jugaba a la taba en las inmediaciones del depósito los días de San Andrés y Santa Lucía. Es posible que esta práctica fuera anterior y tal vez en el contexto de alguna festividad relacionada con los santos. En otras poblaciones se hacen juegos con apuestas en determinados días festivos. La delimitación temporal del juego de la taba en Colmenar tiene hoy una general justificación: «seguir la tradición». Esta tradición, de profundidad temporal desconocida, estuvo parcialmente interrumpida después de la guerra civil, tras entrar en vigor la prohibición de los juegos de azar, aunque se mantuvo contando con cierta condescendencia por parte de las autoridades, celebrando el juego en trastiendas de algunos bares y tabernas. La alusión a la tradición evita conceder demasiada importancia a la delimitación temporal que tiene el juego. No obstante, habría que recordar que, en una población antes fundamentalmente ganadera, de 
fines de noviembre a mediados de diciembre es tiempo en el que tras las "pariciones» de las ovejas se ha comenzado el degüello y venta de corderos para la Navidad, lo que implica una cierta acumulación de dinero. Además, las matanzas se habían ya iniciado y, según se dice, antes entraban en las apuestas de la taba productos de ellas. La delimitación temporal de juegos de azar a días de Feria es bien conocida. En Colmenar sin embargo, no es el caso pues nunca tuvo Feria. Los ganaderos acudían, en otras fechas, a Buitrago y otros lugares. Puede ser parcialmente explicativo del juego festivo una especial acumulación de dinero, debida al cumplimiento de un ciclo económico, pero tal vez sea más importante apuntar a la fiesta como un contexto de redistribución de la riqueza. El juego de azar es un curioso mecanismo de redistribución que - según se cree- puede ayudar a compensar malos resultados económicos. También se piensa que quienes han tenido mejor fortuna en los negocios están en cierta disposición de someter al azar una parte de sus beneficios. Lo que supone una oportunidad para aquellos a quienes los negocios no les fueron tan bien.

Además de la población ganadera, en Colmenar había un importante sector de pequeños comerciantes y artesanos. Para éstos y sobre todo para los empleados es más significativo que a la taba se jugara a fines y primeros de mes. El juego de la taba les unía a todos y proporcionaba la posibilidad de redistribuir riqueza. En la actualidad la estructura de profesiones y de la renta ha cambiado y no puede decirse que sea el único ni el principal juego de azar que puede redistribuir riqueza ${ }^{4}$. La redistribución de la riqueza en el contexto de la fiesta lleva implícita una congregación de la gente en lugares determinados, una intensificación de la interacción social, incluida la implicación en ritos de comensalidad y puesta en marcha de los ciclos sin fin de invitaciones a beber y comer entre amigos, vecinos y conocidos. La redistribución tiene lugar al amparo de la reciprocidad.

Existe una básica y no desdeñable justificación a la doble fecha dispuesta para el juego de la taba: la posibilidad de compensar un segundo día las pérdidas del primero (o la de arriesgar un segundo día las ganancias ob-

4 El cuadro comparado de distribución de la población activa en Colmenar Viejo por sectores es suficientemente expresivo:

\begin{tabular}{|c|c|c|c|}
\hline & 1960 & 1970 & 1975 \\
\hline Agricultura ....... & $45 \%$ & $10 \%$ & $9 \%$ \\
\hline Industria $\ldots \ldots \ldots$ & 11 & 24 & 22 \\
\hline Construcción ....... & 17 & 31 & 27 \\
\hline Servicios . . . . . . . & 27 & 35 & 40 \\
\hline
\end{tabular}

Por otro lado, los principales juegos de azar a los que se acude para redistribuir riqueza son, como en otras partes de España: la lotería, la lotería primitiva y las quinielas. 


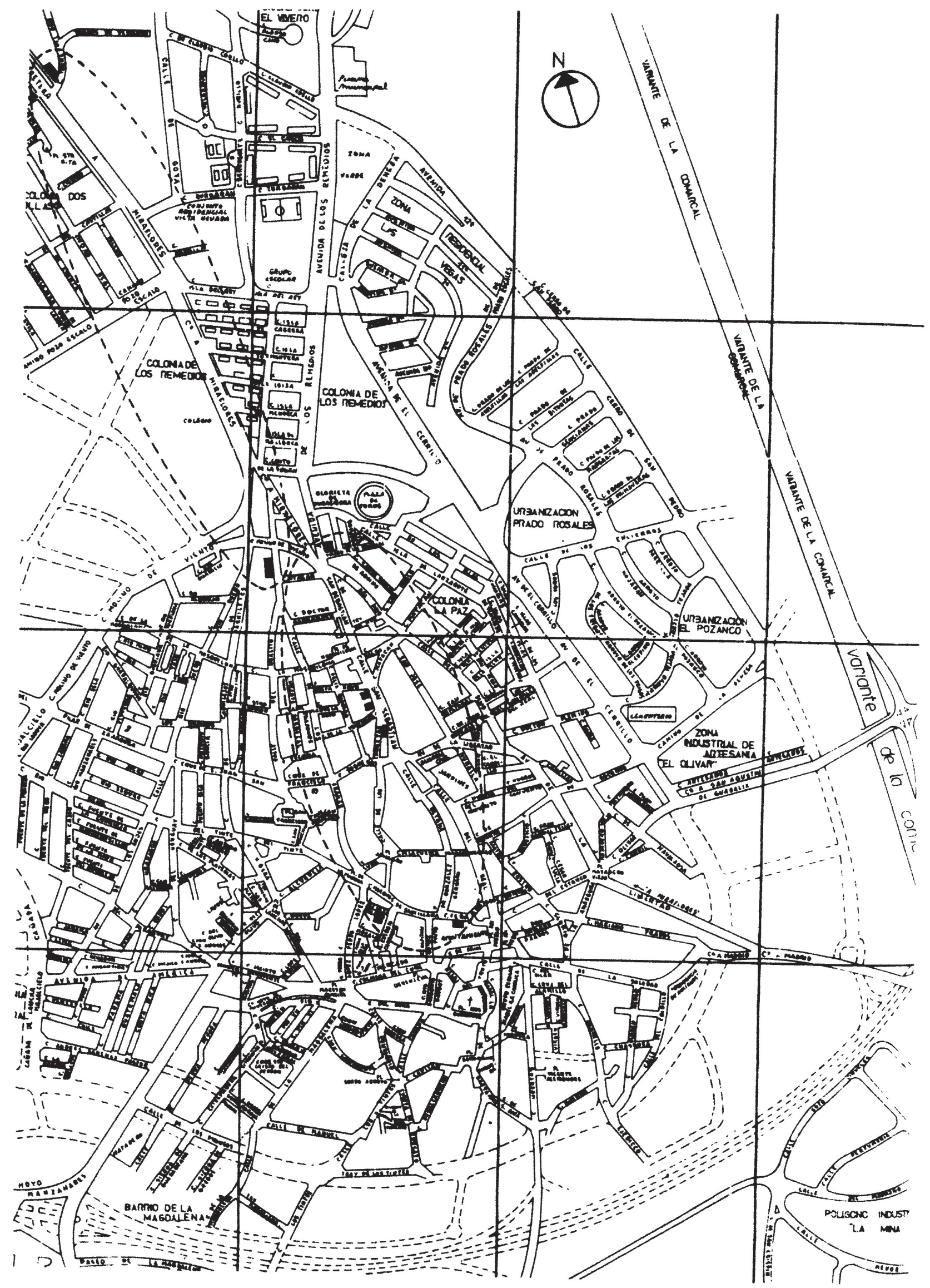

FIG. 2 
tenidas el primero). La doble fecha, sin embargo, debe en principio hacer referencia a la doble advocación de la antigua ermita y a la presumiblemente doble festividad celebrada en ella.

El traslado del juego desde un lugar periférico (el depósito del agua) a un lugar central (los bares) -(fig. 2)- desde después de la guerra civil, tiene una justificación obvia: los jugadores indican unánimemente que por esas fechas el frío obliga a buscar refugio en locales cerrados. El traslado ha comportado la fragmentación en grupos distintos reunidos en bares de lo que antes fue una reunión de todos en un lugar común. Los dueños de los bares - lugares de ocio en donde se concentra la intensificación de las relaciones sociales y el ejercicio de la reciprocidad - han alentado y facilitado el juego proporcionando elementos específicos para desarrollarlo, como mesas, tapetes, tabas, y crupier, por también obvias razones de incremento de sus negocios. Pero el traslado de un lugar común periférico y abierto a múltiples lugares centrales públicos pero relativamente cerrados ha comportado otros cambios. Antes el juego era un espectáculo abierto a hombres, mujeres y niños, que ejercían con su presencia un cierto control social a base de miradas y comentarios sobre desmesurados jugadores. La prohibición y la consiguiente clandestinidad libró al juego de espectadores incómodos. Liberación que continuó luego, asentado ya el juego en los bares, donde la presencia de mujeres y niños a esas horas es infrecuente y en donde además se reúne la clientela habitual y la participación en el juego es en parte un signo de complicidad mutua.

En los últimos años se ha producido otro traslado espacial. Esta vez del centro a la periferia de la población y que comienza a producirse aproximadamente a partir de las once de la noche. El juego, que se inicia hacia las seis de la tarde en determinados bares del centro, acaba en ellos entre las once y las doce y continúa luego en dos locales situados en los nuevos barrios hasta altas horas de la madrugada. Este traslado espacial y a la vez prolongación temporal implica una progresiva búsqueda de espacios más cerrados, más liberados de espectadores incómodos, más adecuados para jugar en serio. La seriedad en el juego parece huir de la presencia de espectadores que pudieran perturbarla con miradas o comentarios sancionadores. El juego, algunos juegos, parecen entenderse como amenazas al orden social.

La multiplicidad de lugares para jugar a la taba apunta hacia alguna diferenciación entre jugadores.

Un primer grupo o conjunto de grupos es el formado por clientes habituales de los respectivos bares céntricos, a los que esos días se añaden otros más ocasionales que acuden expresamente a jugar a la taba. Predominan entre ellos obreros, empleados, pequeños comerciantes y ganaderos. 
El juego puede comenzar a primeras horas de la tarde y a él se incorporan los que van llegando una vez finalizada su jornada de trabajo y continúa hasta las once o doce de la noche, como muy tarde.

Un segundo grupo o conjunto de grupos, menos numeroso que los anteriores, se compone a su vez de clientes habituales y otros más ocasionales, que acuden específicamente esos días a jugar, en los bares periféricos. Predominan entre ellos empresarios de cierto nivel, profesionales liberales y comerciantes (las diferencias sociales entre unos y otros grupos corresponden, a grandes rasgos, a los sectores de población que habitan en la zona céntrica o en los barrios periféricos). Para ellos el juego comienza entrada la noche y acaba ya de madrugada.

Existe además un tercer grupo o conjunto de individuos compuesto por quienes empiezan formando parte del primero y pasan después a integrarse en el segundo, desplazándose de lugar de juego desde los bares del centro a los locales de la periferia. Es menos numeroso que los anteriores. Se trata generalmente de empleados, comerciantes y otros encuadrados en una clase media-baja. Su pertenencia a este grupo depende en buena medida de que haya tenido éxito la estrategia que han diseñado: acumular primero dinero jugando pequeñas cantidades en los bares céntricos desde primeras horas de la tarde, para poder apostar o cubrir mayores apuestas en los locales periféricos ya entrada la noche.

La diferenciación entre estos tres grupos o conjunto de grupos y la relación entre ellos permite dibujar una imagen de una sociedad relativamente estratificada y a la vez alguna de las líneas de movilidad social en ella. En el polo espacial «centro», grupos de jugadores de clase social mediabaja, clientes habituales, que permanecen inmóviles (o en todo caso circulando entre bares de las mismas características). Realizan apuestas de menor cuantía que no llegan a oscilar ostensiblemente entre el momento de inicio del juego al comienzo de la tarde y la hora de cierre del bar.

En el polo espacial «periferia», frecuentando locales de lujo, grupos de jugadores pertenecientes a una clase social media-alta, también clientes habituales y que permanecen inmóviles. La cuantía de sus apuestas es considerablemente mayor y se va elevando progresivamente a medida que transcurre la noche hasta alcanzar un volumen considerable.

Dos grupos o conjuntos de grupos definidos y diferenciados por la ocupación del espacio urbano y la circunscripción de sus movimientos. Y también, por la cantidad de dinero de la que parecen poder disponer para gastos de ocio. Entre estos dos polos, un grupo o conjunto de individuos que se mueve o eleva en la dirección del polo «centro» al polo «periferia» y cuya movilidad parece estar basada en una estrategia que tiene como 
finalidad acumular dinero entre sus iguales hasta poder equipararse al estrato superior.

El juego de la taba es un mecanismo en cierto modo ritualizado de movilidad social. Es sabido que algunas fiestas son contextos en los que se resaltan los valores de la igualdad social, pero los contextos de ocio más cotidianos suelen dar más relieve a la diferenciación social. El juego de la taba tiene algo de fiesta y algo de contexto de ocio cotidiano. Por un lado, se torna expresivo de las distancias sociales, pero por otro, y bajo el común señuelo del dinero, proporciona ocasiones para el encuentro, confrontación o integración entre grupos e individuos de espacios y estratos sociales diferentes.

\section{ROLES DEL JUEGO: INDIVIDUOS Y GRUPOS}

En los bares son abrumadora mayoría los hombres, ya jugando u observando. Desde hace tres años se ve a algunas mujeres apostando o incluso tirando la taba. Coinciden allí jóvenes y hombres de edad madura, pero predominan los de treinta a cuarenta años. Entre la aparente confusión se perfilan diferentes grupos o asociaciones de jugadores. Por un lado, grupos estables de amigos, más amplios o más reducidos, que se reúnen en los lugares habituales, esta vez para constituirse en grupos de jugadores de taba. Por otro, grupos inestables, ocasionales, formados por individuos que son compañeros de trabajo, que comparten una misma profesión o que se consideran iguales en nivel económico y social y que estos días, en parte casualmente, deciden asociarse para jugar. También hay algunos grupos definidos por vinculaciones familiares. $\mathrm{Y}$ además, jugadores solitarios, cuya presencia en los bares no es habitual, aunque entre el resto de jugadores tienen muchos conocidos, y que acuden expresa y únicamente a jugar. $\mathrm{Di}$ fícilmente este espectro puede considerarse una buena muestra de representación del conjunto de la sociedad, salvo tal vez para indicar que una imagen de estratificación y movilidad social ha de entreverarse con la insinuación de complejidad que dan las redes sociales.

Los grupos los conforma el juego y el juego tiene sus roles: tirador, los que cubren la apuesta, el crupier, el prestamista, los observadores. Ninguno de ellos tiene término específico para ser designado. El tirador tira la taba y establece la cuantía de la apuesta, otros la cubren. El crupier ordena el juego, pone a disposición de los tiradores las tabas, establece un turno para tirar, recoge el dinero de la apuesta, lo remite a los ganadores y generalmente recibe una propina de ellos. El prestamista no es que esté siempre presente y no lo está en la mesa de juego, sino rondando por 
allí. Presta dinero si quien se lo pide le merece confianza. Los observadores miran. Algunos esperan su turno para tirar o para cubrir las apuestas.

El rol de tirador lo ejecuta siempre una sola persona, pero a veces juega solo, otras muchas lo hace en nombre de un grupo. Generalmente se trata de un grupo estable, naturalmente formado antes del juego, basado en relaciones de amistad, compañerismo o incluso familiares y permanece como grupo de juego hasta que se decida lo contrario. Quienes lo integran ponen una cierta cantidad de dinero, en unos casos igual, en otros no y reciben ganancias, si las hay, proporcionalmente a lo puesto y expuesto. Si pierden la cantidad inicial, y así lo deciden, vuelven a poner otra vez hasta que se acabe definitivamente o juzguen que deben retirarse.

Se forman también grupos circunstanciales, casi creados en el acto, basados en el interés mutuo, cuya duración es imprevisible, a veces simplemente para una única secuencia de apuestas, luego se disuelven repartiendo ganancias o pérdidas.

Los grupos en torno a un tirador son en todo caso reducidos (dos o tres personas) y raramente numerosos. Se organizan según una determinada división de funciones. Uno tira la taba. Cuando les toca el turno es el mismo el que escoge la taba y la tira. Quién sea del grupo depende del lance, de su «buena suerte» en ocasiones anteriores o de que «esté en racha», etc. Otro se ocupa de las finanzas, recoge el dinero de todos, lo coloca en la mesa y si su compañero saca «carne» y gana, recoge el dinero que le entrega el crupier. Si la ronda de apuestas les es favorable propone a su o sus compañeros retirar parte del dinero ganado y guardarlo. Se sitúa al lado del que tira, algo retirado. Forman un dúo significativamente especializado que exige compenetración y que sugiere una cierta creencia en que las habilidades del juego están disociadas, unas son las propiamente habilidades técnicas (tirar la taba) y otras administrativas (reunir el dinero, establecer estrategias, etc.). No obstante, muchos prefieren tirar solos y solos se encargan de todo, del dinero y de la taba.

Los que cubren la apuesta se sitúan en la mesa a la derecha y en frente del tirador. Son individuos que arriesgan en solitario su dinero o forman grupos distintos, uno de cuyos miembros coloca el dinero en nombre de todos. Grupos previamente formados del modo antes apuntado. Son generalmente más amplios que los de los tiradores. Predominan asociaciones de tres, cuatro, cinco o más personas. No siempre es el mismo el que deposita el dinero sobre la mesa y no se aprecian especializaciones entre ellos. Además, se suelen regir por una norma de igualdad. Todos participan con la misma cantidad y por tanto reparten a partes iguales si hay ganancias. Su permanencia y estabilidad como grupo es notable. Continúan juntos hasta que deciden dejar de jugar. 
Los roles del juego y los lances de éste se prestan pues a diferenciar individuos o grupos, por un lado, y a conformar el tamaño y perdurabilidad de los grupos de modo distinto. Ambos roles pueden ser desempeñados por individuos o por asociaciones de éstos, pero el rol de tirador está más individualizado, el de los que cubren la apuesta tiende más a agrupaciones. El rol de tirador admite mejor grupos reducidos, el de los que cubren la apuesta admite grupos más amplios. El rol de tirador conforma grupos más inestables, dependientes del lance, de la suerte; el de los que cubren la apuesta conforma grupos más estables, más independientes de las veleidades de la fortuna, más sólidos ante los reveses. Evidentemente los que tiran arriesgan más, pierden o ganan más, los que cubren la apuesta arriesgan menos, pierden o ganan menos. Recuérdese que los que tiran apuestan una cantidad cuya totalidad es cubierta por la suma de apuestas menores de distintos y numerosos individuos o grupos. En esencia, juega uno contra todos. El riesgo pone en evidencia no sólo la calidad de las relaciones sociales sino también el valor del tamaño, la densidad y la estabilidad en la dinámica de las asociaciones y los grupos.

Son roles que pueden alternarse, pero de hecho ni los tiradores ni los que cubren las apuestas están muy predispuestos a variar su posición. Aun a pesar de la posibilidad de variarla, los que hacen de tiradores rara vez pasan a cubrir apuestas. Con la ambición de grandes ganancias, prefieren el riesgo de apostar contra todos y suele verse desempeñando ese rol a «especialistas» de los juegos de azar, no sólo de la taba.

Algunas veces grupos o jugadores solitarios que estaban cubriendo apuestas pasan a convertirse en tiradores. Lo que sugiere una posible estrategia de juego entre quienes parten de aceptar riesgos menores, correspondientes razonablemente a una más bien menguada cantidad de dinero disponible, para asumir posteriormente y si la suerte les acompaña, el riesgo de apostar cantidades mayores.

Los que cubren las apuestas suelen permanecer en su sitio a lo largo de varias jugadas, aunque pierdan. Lo que contrasta con la extrema rapidez con la que se suceden en el rol de tirador individuos o grupos, pues para ellos rige una norma por la que, si pierden la apuesta, han de ser sustituidos inmediatamente por aquellos que esperan su turno. El rol de tirador sólo puede ser ocupado de forma continuada por los que ganan. Basta que pierdan una sola vez para que se retiren; lo que a veces da lugar a una sucesión a ritmo acelerado de jugadores que tiran una sola vez, pierden y se van. Los que cubren las apuestas pueden continuar todo el tiempo que lo deseen. Para los tiradores, la norma sirve por un lado para impedir que sus pérdidas se agraven, pero también permite una acumulación importante de dinero, si se tiene una racha de suerte. Para los que cubren 
las apuestas se entiende la no aplicación de la norma de sustitución pues las pérdidas y las ganancias son pequeñas. Dicho sea de otro modo, un tirador arriesga en una sola jugada lo que uno que se limita a cubrir apuestas arriesga en 7,10 ó 12 (según sea el número de apostantes y la cantidad que cubren), suponiendo que se mantenga constante el nivel de la apuesta. Además, esta norma de sustitución y la regla de establecimiento de la apuesta parecen tratar de compensar la desigual probabilidad de que se produzca una serie ininterrumpida de «carne».

El crupier es un rol introducido bastante recientemente. Su presencia coincide con el traslado del juego a los bares, generalizado en la postguerra. El propio dueño del bar, un empleado suyo o alguien especialmente contratado para esos días son quienes hacen de crupier. Se sitúa a un lado de la mesa de juego y con una varita recoge y distribuye el dinero. Marca los límites de tiempo de juego, inicia la ronda de apuestas, toma el dinero que apuesta el tirador y lo va casando con las apuestas menores de los que las cubren. Si los que pretenden esto son más que los que admite la apuesta, establece un orden rotatorio entre ellos. En el caso en el que la cantidad entregada por el tirador no se haya cubierto del todo, le devuelve el dinero sobrante, declara cubiertas las apuestas, recoge la taba y la entrega al tirador cada vez que ésta cae en una posición no significativa, decide sobre la validez de ciertos lances, tales como que la taba toque en algún cuerpo extraño, etc. Pero especialmente controla el flujo del dinero. Entre el tirador y los que cubren las apuestas no se produce una confrontación directa sino mediada por el crupier. $\mathrm{Y}$ no se produce tampoco una entrega directa de dinero, sino a través de él. Esta mediación, distancia y aísla relativamente al tirador respecto a los que cubren las apuestas, le libera de los asuntos que conlleva la apuesta pues es él quien se encarga de animar a apostantes indecisos a cubrirla y de la custodia y distribución del dinero, a veces también hasta de guardar parte del capital acumulado. Esta liberación tiende a facilitar para el tirador la mayor concentración posible, pero es evidente que oculta una interesada intervención del propietario del bar que presta un servicio a cambio de una participación no estipulada, pero debida, en las posibles ganancias. Su mediación disocia taba y dinero. El tirador se ocupa exclusivamente de la taba y se enfrenta a través de ella a todos. Su aislamiento, su individualización acaba siendo un enfrentamiento del individuo con su suerte. El juego cobra entonces toda la seriedad.

El prestamista es un viejo personaje, pero su presencia en el contexto del juego es aún más reciente que la del crupier y ligada especialmente al desarrollo del juego en los bares de la periferia, donde se juega mucho dinero. Presta preferentemente a clientes habituales de estos locales cuando el lance del juego les deja sin blanca y, para poder continuar jugando, ten- 
drían que volver a sus casas a recogerlo. Las cantidades prestadas no suelen ser inferiores a 250.000 pesetas. La presencia del prestamista es indicio de que el juego alcanza gravedad, de que se juega «fuerte».

Los espectadores son numerosos. Se agrupan en torno a la mesa y son testigos de las jugadas, pero no intervienen en ningún momento de ellas. Hay observadores simplemente ocasionales que, como los jugadores ocasionales, acuden todos los años por esas fechas sólo a observar, tal vez a ser testigo de alguna jugada excepcional, y a charlar con algún conocido o amigo. Otros siguen el juego con mayor atención, se sitúan en posiciones estratégicas esperando para ocupar un puesto de jugador e incluirse entre los que cubren las apuestas. El reclutamiento de éstos está garantizado, siempre hay un número potencial de jugadores más o menos dispuestos a participar. Por el contrario, quienes esperan el turno para ocupar el puesto de tirador no suelen seguir las jugadas de sus antecesores, aparentan estar desinteresados e incluso distanciados del lugar de la acción.

Todos ellos forman una entidad social de difícil definición. C. Geertz', para referirse a una agrupación similar generada por la pelea de gallos en Bali, acudió al concepto forjado por Goffman ${ }^{6}$ de «reunión focalizada», algo que no está tan estructurado como un grupo ni tan desestructurado como una multitud, sino «una agrupación de personas reunidas en torno a un flujo común de actividad y relacionadas entre sí en virtud de ese flujo». Tales reuniones focalizadas suelen tomar forma espacial de corro más o menos cerrado. Un corro en el que se dirime la suerte de uno a costa, si es que la alcanza, de la fortuna de muchos es más que una simple focalización. Pese a la disposición espacial a la que obliga el tirar la taba sobre la mesa, el tirador se sitúa socialmente en frente y desplaza la taba al medio y con ella simbólicamente a sí mismo. El camino de la movilidad social es el que va al medio de un corro.

5 C. GeERTZ, La interpretación de las culturas (Barcelona: Gedisa, 1987), p. 348. Estamos citando precisamente el artículo que en cierto modo nos ha servido de inspiración en este trabajo: «Juego profundo: notas sobre la riña de gallos en Bali». Hemos, sin embargo, sustituido el término «juego profundo» por «jugar en serio». Como se sabe, C. Geertz lo toma de J. Bentham, pero cita la traducción al inglés de una anterior traducción al francés de la obra original de Bentham, naturalmente escrita en inglés. Este juego de traducciones, incluyendo la nuestra, impide tomar el término como una categoría universalmente aplicable. Eso no obsta para, una vez usado, explicitar su significado.

6 E. GoffMAN, Encounters: two studies in the Sociology of Interaction (Indianápolis, 1961). 


\section{SECUENCIA DE GANANCIAS Y PÉRDIDAS}

Las vicisitudes del juego no son tantas que no puedan hallarse pautas. Entre los bares céntricos y los de la periferia, entre la etapa vespertina del juego y la etapa nocturna hay diferencias ya señaladas en las cantidades de partida. En los bares del centro se parte a las seis de la tarde de apuestas de 2.000 pts. Hacia las 9 de la noche la cantidad de partida es, por término medio, 14.000 pts. En los bares de la periferia se parte, a eso de las once, de apuestas de 20.000 pts. Hacia las cuatro de la madrugada pueden ser de 45.000 pts. Proporcionalmente, hay mayor incremento en la cuantía de las apuestas en el juego en los bares céntricos que en los de la periferia. Pero en éstos el incremento en pesetas reales es mayor.

Una apuesta puede dar lugar a una posible secuencia de apuestas entre un mismo tirador y aproximadamente los mismos que cubren sus apuestas. Juegan unos y otros al sistema de doble o nada. Este sistema permite una progresión geométrica en la cuantía de la apuesta. Un tirador comienza apostando 2.000, pero a la tercera jugada podría estar apostando 8.000, a la sexta 64.000 y así sucesivamente. Si se comienza apostando 20.000 , a la tercera puede estar apostándose 80.000 , y a la sexta, 640.000.. El juego genera juego, o más exactamente, ganar permite acumular rápidamente dinero para poder seguir jugando y apostando más dinero. El azar permite así a un jugador con suerte ascender por la escala del dinero hasta poder equipararse a aquellos a quienes la herencia, la capacidad y la oportunidad les hicieron superiores a él.

El sistema del doble o nada, sin embargo, funciona como límite. Las secuencias reales de jugadas no siguen siempre la progresión geométrica, sino progresiones aritméticas ${ }^{7}$. Si se gana, la siguiente apuesta debe ser

7 Como muestra etnográfica, he aquí algunas secuencias de jugadas en un bar céntrico hacia las 9 de la noche el 13 de diciembre de 1988. Las siguientes son diferentes secuencias de apuestas de distintos y sucesivos tiradores de taba:

1. 1. Un jugador apuesta 20.000 pts., que son cubiertas por varias personas. Gana.

2. El mismo tirador apuesta en la segunda jugada otras 20.000 , pero pierde y se retira.

2. 1. Otro tirador apuesta en la primera jugada 22.000;

2. en la segunda, 31.500 ;

3. en la tercera 50.000 , pierde y se retira.

3. 1. 12.000;

2. 24.000 , pierde.

4. 1. 10.000;

2. 20.000

3. 40.000;

4. 25.000 , pierde. 
mayor que la anterior, pero no necesariamente el doble. Por dos razones: una, como estrategia de un tirador "prudente», que salvaguarda una parte de lo ganado ante el riesgo de perderlo todo, y dos, como estrategia de aquellos que cubren la apuesta, que, ante la mayor cuantía de la apuesta y la consiguiente exigencia de más dinero para cubrirla, se retraen poniendo sobre la mesa menos dinero en conjunto del solicitado. Obsérvese que una apuesta de mayor cuantía que la anterior puede ser cubierta o con más dinero (y los mismos apostantes) o con más apostantes (y el mismo dinero). El rol de cubrir la apuesta cobija a gentes que tienden a asumir menores riesgos, por lo que no aceptan fácilmente mayores cantidades. Eso implica que en apuestas mayores la confrontación uno contra todos podría extenderse. El «todos» podría hacerse progresivamente más amplio cuanto más alta es la apuesta de un tirador. La ambición de dinero podría llegar a provocar una confrontación general. Sin embargo, no ocurre generalmente así. Evidentemente, ante una secuencia de ganancias continuadas por parte de un tirador crece la expectación, pero el número de quienes cubren la apuesta no se va haciendo necesariamente mayor. Es decir, a pesar de todo, llegan a jugar cantidades más importantes y afrontan riesgos mayores. Posiblemente sea así porque una serie continuada de ganancias se entienda como improbable.

Cada jugada es teóricamente independiente, pero la secuencia les niega independencia y tiende a hacerlas percibir conexionadas. Aparece la «racha». Una buena (o mala) racha es una serie de jugadas sucesivas de igual resultado. Se piensa que la probabilidad de sacar «carne» una serie de veces disminuye progresivamente, de modo que un alto número de veces seguidas en las que sale «carne» es considerado sorprendente, casi increíble. Se dice que alguno ha llegado a obtener «carne» hasta 14 ó 15 veces seguidas.

5. 1. 10.000;

2. 18.000 , pierde.

6. 1. 10.000;

2. 20.000

3. 40.000

4. 65.000 ;

5. 83.000 , pierde.

7. 1. 20.000;

2. 40.000

3. 55.000

4. 85.000

5. 130.000 , pierde.

Con estas 7 secuencias hubo otras 11 que sólo constaron de una jugada, pues cada uno de esos otros 11 jugadores perdieron en la primera y única ocasión que tuvieron oportunidad de jugar. 
Conseguirlo 5 ó 6 veces seguidas ya empieza a ser extraordinario. La «suerte» parece considerarse veleidosa. Consiste regularmente en episodios alternados de «buena» y «mala suerte». La alternancia, sin embargo, no es regular, ni predecible. No se conoce cuándo va a cambiar, ni con qué ritmo. Es, sin embargo, predecible que una serie continuada de episodios de «buena» o de «mala suerte» no puede durar mucho, no puede ser ilimitada. Pero la «suerte» entra en rachas. Los ciclos de la suerte son de distinta amplitud y siempre cabe la posibilidad de entrar en la fase «buena» de un ciclo largo, una serie continuada de ganancias. El tirador de taba juega con esa posibilidad, los cubridores de apuestas juegan a la suerte veleidosa. El tirador de taba busca, tienta su suerte; los que cubren las apuestas parecen limitarse a esperar que no la encuentre. Su esperanza puede debilitarse si le ven ganar unas cuantas veces seguidas, pero se acrecienta si le ven continuar tentando a su suerte y parecen estar convencidos de que caerá, por eso permanecen en sus puestos, poniendo sobre la mesa cantidades mayores. Esperan así recuperar en una jugada aciaga para el tirador un dinero que él les arrebató en muchas.

El fin de una secuencia es variable. Cuatro son los posibles resultados finales. (Propiamente, resultados finales relativos, pues no se cuenta aquí que un jugador - ya sea como tirador o cubriendo apuestas- pueda implicarse en otra u otras secuencias posteriores):

1. La paridad. El tirador y los que cubren las apuestas llegan a tener, al fin de una secuencia de jugadas, una cantidad de dinero aproximadamente igual a aquélla con la que uno y otros empezaron. Esto se consigue mediante la estrategia, por parte del tirador, de retirar en cualquiera de las jugadas primeras de «carne» una cantidad equivalente a la que fue su apuesta inicial. Luego, si va jugándose todo lo que gana y le sale «culo», queda como estaba y los que cubren las apuestas recuperan su dinero. Normalmente, la secuencia no es demasiado larga; dura tres o cuatro jugadas a lo más.

2. Paridad relativa. La secuencia se produce como en el caso anterior. Con la salvedad de que el crupier recibe de un tirador que gana en una jugada una cierta cantidad. Esta cantidad la recoge inmediatamente después de que el tirador haya ganado y antes de «casar» la apuesta siguiente, o bien de «casar» ésta y no haberse podido cubrir toda. Ese dinero sin cubrir se lo queda el crupier. De todos modos, sólo recibe dinero a partir del segundo lance del juego, nunca a partir del primero. Si el tirador ha retirado la cantidad de su apuesta inicial y el crupier ha recibido parte de sus ganancias, el resto apostado y perdido, es decir recuperado por los que cubren las apuestas, es menor que la cantidad de partida precisamente en lo que se llevó el crupier. 
3. El tirador pierde (los que cubren las apuestas ganan). Uno es el caso de una secuencia - propiamente no tal- de una jugada. El tirador pierde lo apostado y deja de tirar. Los que cubren la apuesta ganan y ganan poco, porque son varios a repartir y porque las primeras jugadas son de apuestas bajas. Otro es el caso de secuencias de varias jugadas en las que el tirador juega al doble o nada (o bien reserva algunas cantidades que no llegan a igualar la apuesta inicial). Los que cubren las apuestas no sólo acaban recuperando su dinero, sino también ganando lo que el tirador pierde. Siendo muchos, la ganancia total no es alta. El crupier nada se lleva si el tirador pierde.

4. El tirador gana (los que cubren las apuestas pierden). Un tirador en racha va sacando «carne» jugada tras jugada. De las ganancias reserva y guarda una parte, de modo que la apuesta siguiente es mayor que la anterior, pero no el doble que la anterior. A medida que suma ganancias y que las apuestas crecen el juego gana en expectación. Acuden más espectadores. Los que cubren las apuestas resisten esperando que falle. Mientras tanto, van perdiendo dinero paulatinamente e incrementando sus pérdidas. Cuando finalmente se rompe la secuencia, recuperan algo de lo perdido, pero el tirador acaba ganando todo aquello que tras cada jugada victoriosa fue reservando.

Si tras una secuencia el tirador pierde, pierde más cantidad que la que cualquiera de los que cubren las apuestas gana. Éstos ganan a costa de un tirador sin suerte, pero sus ganancias siempre son menguadas. Si tras una secuencia el tirador gana, gana a costa de los que cubrieron sus apuestas y gana importantes cantidades. Los que cubrieron sus apuestas pierden, pero sus pérdidas son reducidas, si se tiene en cuenta que las soportan entre todos.

\section{SAN ANDRÉS Y LA SUERTE}

A medida que se juega más «fuerte», es decir, se apuestan más cantidades de dinero, el juego se hace más «serio». Podría llegarse a jugar tan «fuerte» que se apostara el patrimonio, los negocios, los bienes inmuebles $y$, según se dice, hasta la mujer. El juego habría cruzado entonces el límite de la «seriedad» y se consideraría una transgresión. En el discurso mítico del juego de la taba en Colmenar no faltan leyendas sobre jugadores que llegaron a jugarse casa, hacienda y mujer, y perdieron. Estas narraciones refieren siempre hechos sucedidos hace años. Aparecen en contexto entre espectadores y parecen adquirir verosimilitud cuando se asiste a una secuencia ininterrumpida de ganancias por parte de un tirador y ya el vo- 
lumen de lo apostado en una sola jugada es muy alto. Si la secuencia continuara, de forma que la siguiente apuesta no pudiera cubrirse con dinero contante que no se tiene, y se aceptara, exigiría cubrirse con el patrimonio.

La leyenda parece cernirse como una especie de maldición sobre aquellos tiradores de taba tan desesperados que, tras continuos fracasos con su suerte, agotado ya el dinero, pretendieron recuperarse apostando lo que no debían. En realidad, un narrador de estas leyendas puede utilizarlas tanto moralizadoramente como para reforzar el apasionamiento por el juego, la mutación de jerarquía de valores que la inmersión en el juego puede llegar a provocar. La leyenda es tanto un arma de censura como un elogio de la capacidad de atracción del juego. La posibilidad de que un tirador de taba llegue a jugarse casa, hacienda y mujer estaría en hacerlo en una única, última y definitiva jugada (o bien en pagar con eso al prestamista que le fue proporcionando el dinero que perdió en el juego). Pero curiosamente la leyenda de quienes llegaron a jugarse casa, hacienda y mujer no debería hacer referencia a quienes son tiradores de la taba, pues si la suerte les ha acompañado han podido acumular dinero bastante como para permitirse arriesgar todo cuanto han ganado y formular una apuesta desmesurada. Debería hacer referencia más bien a quienes han cubierto apuestas sucesivas de ese tirador afortunado y, por lo tanto, han ido perdiendo cuanto tenían y quedándose solos ante él aceptan un último desafío, con la esperanza de que su suerte finalmente cambie. Ése es el momento en el que se podría cumplir la movilidad social que el juego de la taba dinamiza. Un tirador con suerte, partiendo de la nada, podría llegar a tenerlo todo a costa de aquellos insensatos que aceptaran su apuesta.

Pero los jugadores han ido desarrollando estrategias que tienden a impedirlo. Esas jugadas míticas no llegan a tener lugar, porque se adoptan estrategias especiales, estrategias sociales. El juego como mecanismo de movilidad social muestra que un jugador ambicioso debe enfrentarse a todos sus iguales. Eso significa individualizarse frente a ellos. Si gana, si les gana, estará en disposición de enfrentarse a otros antes superiores a él. De todos modos, los que acepten su apuesta, si pierden, perderán poco, siempre que sean muchos y repartan el riesgo entre todos. Pero además, en la práctica, los que cubren apuestas forman grupos relativamente numerosos, lo que minimiza aún más el riesgo y, por tanto, reduce aún más las pérdidas. Eso teniendo en cuenta que, por lo general, los grupos de juego no son grupos domésticos - verdaderos referentes de la propiedad del dinerosino grupos formados sobre redes sociales, es decir, grupos de edad, de amigos, vecinos, etc. La leyenda, pues, del mismo modo que prefigura el destino de un tirador de taba empedernido, condena al mismo destino a aquél que trata de cubrir apuestas solo, sin ampararse en el grupo. En 
uno y en otro caso la mala suerte en el juego se traduce en mala suerte en la vida. $Y$ se llega así a situarse en la mayor seriedad. En uno y otro caso la mala suerte es consecuencia del enfrentamiento o la separación del grupo.

Como contrapartida a las leyendas de jugadores que llegaron a jugarse casa, hacienda y mujer se enuncia el casi enigmático dicho de: «San Andrés jugaba a la taba, tanto perdía como ganaba». No hay en la hagiografía de San Andrés episodio alguno ${ }^{8}$ sobre su intervención en el juego. San Andrés aparece aquí como un símbolo generalizado de cualquier jugador de Colmenar; como si tuviera razón esa sugerencia etimológica de que «Andrés» «deriva de ander (varón) y significa hermoso, firme, varonil»". Eso además implicaría que una de las expresiones de virilidad sería adoptar riesgos en el juego. Opinión hoy seguramente menos compartida que antaño. Pero el dicho tiene muy diferentes lecturas. Por un lado, afirma las veleidades de la suerte. Quien juega, unas veces gana y otras pierde, y tanto puede ganar como perder. Esto se aplica a la desigual fortuna de los tiradores y alienta la esperanza en los que cubren la apuesta de que a un tirador no le puede durar la suerte indefinidamente.

Por otro lado, el dicho enuncia un resultado final de igualdad, de paridad. Quien se pone a jugar debe saber que al final va a quedar aproximadamente igual a como comenzó. Ganancias y pérdidas se compensan finalmente, pese a que lances concretos del juego aventuren que va a acabarse perdiendo (o ganando). Además, después de San Andrés viene Santa Lucía, y con ello una posibilidad de recuperarse de un día aciago o de perder lo ganado. Los dos roles básicos del juego proporcionan una de las claves para la comprensión de un resultado final de paridad. Quien adopta el rol de tirador asume mayores riesgos, puede acabar perdiendo. Pero podría recuperarse a continuación poco a poco situándose en el rol de cubrir apuestas, asumiendo riesgos menores y recogiendo parte de lo que otros tiradores también pierden. La garantía de paridad final está, sin embargo, no tanto en los roles - que no suelen alternarse- cuanto en mantenerse en juego formando parte de un grupo. Lo que niega el posible cumplimiento de la movilidad social que teóricamente facilita el juego.

Otra lectura más del dicho alude al doble y simultáneo efecto de pérdidas y ganancias que una misma jugada tiene para un tirador y para los que cubren la apuesta. Si uno gana, los otros pierden, si éstos ganan, aquél pierde. San Andrés podía ser invocado por unos y por otros. Así que «tanto perdía, como ganaba». El juego muestra que la suerte es difícilmente ge-

8 Santiago de la Vorágine, La leyenda dorada (Madrid: Alianza, 1982), pp. 29-37.

Santiago de la VoráGINE, op. cit., p. 29. 
neral. Cuando para unos es «buena», para otros «mala». El juego hace circular el dinero. Con el juego de la taba el dinero se instrumentaliza para una posible movilidad social. Quienes juegan saben -y el dicho se lo declara- que se juega tanto para ganar como para perder, pero lo que unos ganan, otros lo pierden. Planea aquí una cierta sombra de la imagen del bien limitado ${ }^{10}$.

Cualquiera de las lecturas del dicho puede hacerse para circunstancias y situaciones de juego diferentes. Para quien sufre un revés, para aquél a quien la fortuna le sonríe, para quien acaba como empezó, para quien perdió y ve que otro salió ganando, incluso para quien es espectador y contempla cómo la suerte agita la vida social de un pueblo *.

\section{HONORIO M. VELASCO \\ ROBERTO FERNÁNDEZ \\ U.N.E.D., Madrid}

En Colmenar, una población madrileña, para los niños, el juego de la taba distribuía distintas "posiciones» sociales; para los adultos, sin embargo, y en determinados días del año, San Andrés (30 de noviembre) y Santa Lucía (13 de diciembre), es un juego de apuestas que hace circular el dinero y pudiera hacer posible una movilidad social. Se distinguen diferentes grupos de jugadores según el lugar, la hora de juego y la cuantía de la apuesta. El juego enfrenta en esencia a uno contra todos. Una de las vías teóricas para la movilidad social. El riesgo que eso comporta es reducido por medio de una serie de estrategias, relativas tanto a la adopción de uno u otro rol en el juego como a la formación de grupos.

In Colmenar, a town near Madrid, the kids played with the «taba» and distributed fictitious social positions. On 30th November and 13th December the men play with the «taba», they bet money and it could be possible a change in the social positions. There are different groups of players at the different places, times and bets. Essentially in the game one person is against people. That is a possible way of the social change. The risk is reduced by a series of strategies, related to the occupation of the game's roles and related to the integration into the groups too.

10 G. M. Foster, Tzintzuntzan (México: Fondo de Cultura Económica, 1972), pp. 124-151. Una teoría que ha generado cierta controversia. Véase J. M. ACHESON, «Limited Good or Limited Goods: Response to Economic Opportunity in a Tarascan Pueblo», American Anthropologist, 74 (1972), pp. 1152-1169. Por otra parte, el dicho enuncia con singular precisión esa modalidad que la teoría de juegos llama «de suma cero». Comentario que agradecemos a Francisco Álvarez.

* El dibujo de la taba y el plano son obra de Rosa García Blázquez y de Pablo Colmenarejo Romera, a quienes agradecemos su colaboración. 